\title{
A genome-guided analysis of energy conservation in the thermophilic, cytochrome-free acetogenic bacterium Thermoanaerobacter kivui
}

Verena Hess ${ }^{1 \dagger}$, Anja Poehlein ${ }^{2 \dagger}$, Marie Charlotte Weghoff ${ }^{1}$, Rolf Daniel ${ }^{2}$ and Volker Müller ${ }^{1 *}$

\begin{abstract}
Background: Acetogenic bacteria are able to use $\mathrm{CO}_{2}$ as terminal electron acceptor of an anaerobic respiration, thereby producing acetate with electrons coming from $\mathrm{H}_{2}$. Due to this feature, acetogens came into focus as platforms to produce biocommodities from waste gases such as $\mathrm{H}_{2}+\mathrm{CO}_{2}$ and/or $\mathrm{CO}$. A prerequisite for metabolic engineering is a detailed understanding of the mechanisms of ATP synthesis and electron-transfer reactions to ensure redox homeostasis. Acetogenesis involves the reduction of $\mathrm{CO}_{2}$ to acetate via soluble enzymes and is coupled to energy conservation by a chemiosmotic mechanism. The membrane-bound module, acting as an ion pump, was of special interest for decades and recently, an Rnf complex was shown to couple electron flow from reduced ferredoxin to $\mathrm{NAD}^{+}$with the export of $\mathrm{Na}^{+}$in Acetobacterium woodii. However, not all acetogens have rnf genes in their genome. In order to gain further insights into energy conservation of non-Rnf-containing, thermophilic acetogens, we sequenced the genome of Thermoanaerobacter kivui.

Results: The genome of Thermoanaerobacter kivui comprises $2.9 \mathrm{Mbp}$ with a $\mathrm{G}+\mathrm{C}$ content of $35 \%$ and 2,378 protein encoding orfs. Neither autotrophic growth nor acetate formation from $\mathrm{H}_{2}+\mathrm{CO}_{2}$ was dependent on $\mathrm{Na}^{+}$ and acetate formation was inhibited by a protonophore, indicating that $\mathrm{H}^{+}$is used as coupling ion for primary bioenergetics. This is consistent with the finding that the $c$ subunit of the $F_{1} F_{\odot}$ ATP synthase does not have the conserved $\mathrm{Na}^{+}$binding motif. A search for potential $\mathrm{H}^{+}$-translocating, membrane-bound protein complexes revealed genes potentially encoding two different proton-reducing, energy-conserving hydrogenases (Ech).

Conclusions: The thermophilic acetogen T. kivui does not use $\mathrm{Na}^{+}$but $\mathrm{H}^{+}$for chemiosmotic ATP synthesis. It does not contain cytochromes and the electrochemical proton gradient is most likely established by an energy-conserving hydrogenase (Ech). Its thermophilic nature and the efficient conversion of $\mathrm{H}_{2}+\mathrm{CO}_{2}$ make T. kivui an interesting acetogen to be used for the production of biocommodities in industrial micobiology. Furthermore, our experimental data as well as the increasing number of sequenced genomes of acetogenic bacteria supported the new classification of acetogens into two groups: Rnf- and Ech-containing acetogens.
\end{abstract}

Keywords: Acetogen, Thermoanaerobacter kivui, Energy conservation, Genome sequence, $\mathrm{H}^{+}$transport, Ech

\footnotetext{
* Correspondence: vmueller@bio.uni-frankfurt.de

${ }^{\dagger}$ Equal contributors

'Department of Molecular Microbiology \& Bioenergetics, Institute of Molecular Biosciences, Johann Wolfgang Goethe University Frankfurt/Main, Max-von-Laue-Str. 9, 60438 Frankfurt, Germany

Full list of author information is available at the end of the article
} 


\section{Background}

Acetogenic bacteria represent an ecologically important group of anaerobes that are ubiquitous in nature [1]. They constitute the penultimate limb in the anaerobic food web and convert a number of substrates exclusively to acetate, which is then converted by methanogenic archaea to methane, the final product of anaerobic food webs [2]. Acetogens convert hexoses to three moles of acetate according to:

$$
1 \mathrm{C}_{6} \mathrm{H}_{12} \mathrm{O}_{6} \rightarrow 3 \mathrm{CH}_{3} \mathrm{COOH}
$$

indicating the presence of a pathway that is able to reduce two moles of $\mathrm{CO}_{2}$ to acetate [3]. This pathway has been elucidated mainly in the thermophilic species Moorella thermoacetica (formerly Clostridum thermoaceticum) and is named according to its discoverers as the WoodLjungdahl pathway (WLP) [4]. It involves two branches and each of them contributes to the reduction of one molecule of $\mathrm{CO}_{2}$. In the carbonyl branch, $\mathrm{CO}_{2}$ is reduced to enzymebound $\mathrm{CO}$ by the $\mathrm{CO}$ dehydrogenase/acetyl-CoA synthase (CODH/ACS). Electrons for this reduction are provided by reduced ferredoxin [5-7]. In the methyl branch of the WLP, another molecule $\mathrm{CO}_{2}$ is reduced first to formate, which is then activated to formyl-THF in an ATP-dependent reaction $[8,9]$. Subsequently, formyl-THF is converted to methenyl-THF and then reduced stepwise to methyl-THF via methylene-THF. Eventually, the methyl group and the enzyme-bound $\mathrm{CO}$ are joined to form acetyl-CoA, catalyzed by the key enzyme of the WLP, the CODH/ACS [5-7,10-12]. Subsequently, acetyl-CoA is converted to acetyl-phosphate and acetate [13,14]. The latter step involves the production of ATP by an acetate kinase. However, since one mole of ATP is consumed during activation of formate, there is no net ATP gain by substrate level phosphorylation in the WLP. The WLP also enables lithotrophic growth of acetogens on $\mathrm{H}_{2}+\mathrm{CO}_{2}$ according to:

$$
4 \mathrm{H}_{2}+2 \mathrm{CO}_{2} \rightarrow \mathrm{CH}_{3} \mathrm{COOH}+2 \mathrm{H}_{2} \mathrm{O}
$$

and, therefore, additional energy must be conserved by a chemiosmotic mechanism. The chemiosmotic process of energy conservation was recently uncovered in Acetobacterium woodii. A soluble, electron bifurcating, ferredoxin- and $\mathrm{NAD}^{+}$- reducing hydrogenase oxidizes molecular hydrogen and generates a reduced electron carrier with a very low redox potential, ferredoxin $\left(\mathrm{E}^{0} \approx-500 \mathrm{mV}\right.$; a redox potential in this range has to be assumed since a ferredoxin is the electron donor for the $\mathrm{CO}_{2} / \mathrm{CO}$ couple $\mathrm{E}^{0,}=-520 \mathrm{mV}$ ). Reduced ferredoxin is then oxidized by a membranebound ferredoxin: $\mathrm{NAD}^{+}$-oxidoreductase encoded by the rnf genes and therefore also termed Rnf complex. The Rnf complex is composed of six subunits that harbor (covalently-bound) flavins and iron sulfur centers as electron carriers, and the electrons are transferred to the acceptor $\mathrm{NAD}^{+}$[15]. Electron transfer from reduced ferredoxin to $\mathrm{NAD}^{+}$is exergonic and this electron transfer is used to expel sodium ions from the cytoplasm thus generating an electrochemical sodium ion gradient across the membrane [16]. The electrochemical $\mathrm{Na}^{+}$gradient then drives the synthesis of ATP via a $\mathrm{Na}^{+}-\mathrm{F}_{1} \mathrm{~F}_{\mathrm{O}}$ ATP synthase $[17,18]$. The energy-conserving module in $A$. woodii thus comprises only one coupling site, the Rnf complex, and a $\mathrm{Na}^{+}-\mathrm{F}_{1} \mathrm{~F}_{\mathrm{O}}$ ATP synthase. Acetogenesis in A. woodii therefore has a modular appearance: An energyconserving module that is connected to the WLP module by soluble electron carriers such as pyridine nucleotides and ferredoxin. The WLP module is not energy conserving, it serves the function to reoxidize the end products of the anaerobic respiration and to provide acetyl-CoA for biomass synthesis [19].

The use of two different modules for energy conservation and re-oxidation of reduced electron carriers (WLP) opens interesting possibilities for biotechnological applications. In principal, any reductive pathway can be coupled to the energy-conserving module and indeed, acetogens are known that reduce nitrate [20,21], phenylacrylates $[22,23]$ and fumarate $[24,25]$, or acetyl-CoA to ethanol [26] or butyrate $[27,28]$. Very recently, the genetic coupling of a butanol-production pathway to the energy-conserving module proved successful in Clostridium ljungdahlii [29]. Production of biocommodities at high temperatures has several advantages such as lower costs for cooling and distillation or lower risk of contaminations. The genome of the thermophilic acetogen $M$. thermoacetica $\left(\mathrm{T}_{\mathrm{opt}}: 55-60^{\circ} \mathrm{C}\right)$ has been sequenced [30] and the way(s) of energy conservation can be predicted from the genome as well as experimental analyses [31]. Unfortunately, this thermophilic model strain grows poorly on $\mathrm{H}_{2}+\mathrm{CO}_{2}$ (doubling times of up to $24 \mathrm{~h}$ [32]), a substrate used for 3rd generation biotechnology, thus limiting its use in industrial microbiology. In contrast, the acetogen Thermoanaerobacter kivui grows very fast on $\mathrm{H}_{2}+\mathrm{CO}_{2}$ with doubling times around $2 \mathrm{~h}$ and has an even higher $\mathrm{T}_{\text {opt }}$ of $66^{\circ} \mathrm{C}$ [33]. Moreover, its acetate to biomass ratio was about half compared to $M$. thermoacetica indicating a more efficient way to conserve energy [34]. This is also exemplified by yield measurements: $97 \%$ more biomass is produced from one mole of $\mathrm{H}_{2}$ in $T$. kivui compared to $M$. thermoacetica [34]. This prompted us to sequence the genome of T. kivui to predict by bioinformatic analyses followed by experimental analyses how this acetogen couples acetogenesis to chemiosmotic energy conservation.

\section{Methods}

\section{Growth conditions}

T. kivui LKT-1 (DSM 2030) was grown at $65^{\circ} \mathrm{C}$ in medium that was prepared as described by Leigh et al. 
[33] with some modifications. Complex medium contained: $50 \mathrm{mM} \mathrm{NaH}{ }_{2} \mathrm{PO}_{4}, 50 \mathrm{mM} \mathrm{Na} \mathrm{HPO}_{4}, 1.2 \mathrm{mM} \mathrm{K}_{2} \mathrm{HPO}_{4}$, $1.6 \mathrm{mM} \mathrm{KH} \mathrm{PO}_{4}, 4.7 \mathrm{mM} \mathrm{NH} \mathrm{NH}_{4} \mathrm{Cl}, 1.7 \mathrm{mM}\left(\mathrm{NH}_{4}\right)_{2} \mathrm{SO}_{4}$, $7.5 \mathrm{mM} \mathrm{NaCl}, 0.37 \mathrm{mM} \mathrm{MgSO}_{4}, 42 \mu \mathrm{M} \mathrm{CaCl}_{2}, 7.2 \mu \mathrm{M} \mathrm{Fe}$ (II) $\mathrm{SO}_{4}, 54 \mathrm{mM} \mathrm{NaHCO}, 3 \mathrm{mM}$ cysteine- $\mathrm{HCl}, 0.2 \%$ $[\mathrm{w} / \mathrm{v}]$ yeast extract, $1.0 \%[\mathrm{v} / \mathrm{v}]$ trace element solution (DSM 141), 1.0\% [v/v] vitamin solution (DSM 141), and $4 \mu \mathrm{M}$ resazurin. Glucose was added as a carbon source from an autoclaved anoxic stock solution to a final concentration of $28 \mathrm{mM}$. All vessels were pressurized with 1 bar $\mathrm{N}_{2}: \mathrm{CO}_{2}(80: 20[\mathrm{v} / \mathrm{v}])$. Growth experiments for determination of $\mathrm{Na}^{+}$-dependence of autotrophic growth were performed exactly as described by Yang \& Drake [35]. The contaminating amount of $\mathrm{Na}^{+}$was $160 \pm 4 \mu \mathrm{M}$, determined using an Orion Star A214 $\mathrm{Na}^{+}$-selective electrode (Thermo Scientific, USA). Growth was determined by measuring the optical density at $660 \mathrm{~nm}\left(\mathrm{OD}_{660}\right)$ with a spectrophotometer.

\section{Preparation of membranes from T. kivui}

Cells were grown to an optical density at $600 \mathrm{~nm}$ of $1.9-$ 2.4 as described in $2 \times 500 \mathrm{ml}$ complex medium in 1-1flasks (Glasgerätebau Ochs, Bovenden-Lenglern, Germany) with $28 \mathrm{mM}$ glucose as carbon source and harvested anaerobically by centrifugation at $11,500 \times \mathrm{g}$ for $10 \mathrm{~min}$ at $4^{\circ} \mathrm{C}$. Cells were washed once in buffer A $(50 \mathrm{mM}$ Tris, $20 \mathrm{mM} \mathrm{MgSO}_{4}, 20 \%$ glycerol, $2 \mathrm{mM}$ DTE, $4 \mu \mathrm{M}$ resazurin, $\mathrm{pH} 7.5)$ and, after another centrifugation step, resuspended in 5-10 ml buffer A. Cells were disrupted by a single passage through a French press $(110 \mathrm{MPa})$. Cell debris and whole cells were removed by a centrifugation step for 30 minutes at 23,700 $\times$ g and $4^{\circ} \mathrm{C}$. The cell extract was separated into the cytoplasmic and membrane fraction by ultracentrifugation $\left(150,000 \times \mathrm{g}, 2 \mathrm{~h}, 4^{\circ} \mathrm{C}\right)$. The membranes were washed once in buffer A and sedimented again via ultracentrifugation. Finally, the membranes were resuspended in $\sim 5 \mathrm{ml}$ buffer A and used immediately for the measurement of $\mathrm{Fd}_{\text {red: }}$ : $\mathrm{NAD}^{+}$oxidoreductase activity. Protein concentrations were determined as described previously [36].

\section{Measurement of $\mathrm{Fd}_{\text {red }}: \mathrm{NAD}^{+}$oxidoreductase activity}

Measurement of electron transfer from reduced ferredoxin to $\mathrm{NAD}^{+}$was performed as described [37] at $60^{\circ} \mathrm{C}$ in anaerobic cuvettes filled with $1 \mathrm{ml} 20 \mathrm{mM}$ Tris- $\mathrm{HCl}$ buffer (pH 7.7) containing $20 \mathrm{mM} \mathrm{NaCl}, 2 \mathrm{mM}$ DTE and $4 \mu \mathrm{M}$ resazurin at a pressure of $0.5 \times 10^{5} \mathrm{~Pa} \mathrm{CO}$. Ferredoxin $(30 \mu \mathrm{M}$; purified from C. pasteurianum as described [38]), CODH/ACS (30 $\mu \mathrm{g} / \mathrm{ml}$; purified from A. woodii as described [37], and washed membranes $(150 \mu \mathrm{g} / \mathrm{ml})$ were added. The reaction was started by addition of $\mathrm{NAD}^{+}$ (4 mM). Formation of NADH was measured at $340 \mathrm{~nm}$.

\section{Isolation of chromosomal DNA}

Chromosomal DNA of T. kivui was isolated according to the procedure described [39] and modified by Ausubel et al. [40].

\section{Sequencing strategy}

The genome of $T$. kivui was sequenced with a combined approach using the 454 GS-FLX Titanium XL system (Titanium GS70 chemistry, Roche Life Science, Mannheim, Germany) and the MiSeq (Illumina, San Diego, CA). Shotgun libraries were prepared according to the manufacturer's protocols, resulting in 110,391 reads for 454 shotgun sequencing and 5,916,460 150-bp paired-end reads for Illumina sequencing. All of the 454 shotgun reads and 1 Mio 150-bp paired-end Illumina reads were used for the initial hybrid de novo assembly with MIRA 3.4 [41] and Newbler 2.8 (Roche Life Science, Mannheim, Germany). The final assembly contained 42 contigs with an average coverage of 89.20. For scaffolding and contig ordering tasks we used the Move Contigs tool of the Mauve Genome Alignment Software [42] and the genomes of T.mathranii mathranii A3, DSM 11426, T. brockii finii Ako-1, DSM 3389 and T. wiegelii Rt8.B1 as references. Additionally, contigs that could not be ordered with Mauve were examined via Gene Ortholog Neighborhoods based on bidirectional best hits implemented at the IMG-ER (Integrated Microbial Genomes-Expert Review) system [43,44] and with multiplex PCR [45]. Sequence gaps were closed in the Gap4 (v.4.11) software of the Staden Package [46] by PCR-based techniques and primer walking with conventional Sanger sequencing, using BigDye 3.0 chemistry on an ABI3730XL capillary sequencer (Applied Biosystems, Life Technologies $\mathrm{GmbH}$, Darmstadt, Germany).

\section{Gene prediction and annotation and analysis}

The software tool prodigal (Prokaryotic Dynamic Programming Genefinding Algorithm) [47] was used for automatic gene prediction, while identification of rRNA and tRNA genes was performed with RNAmmer and tRNAscan, respectively $[48,49]$. Automatic annotation was carried out with the IMG-ER (Integrated Microbial Genomes-Expert Review) system [43,44], but annotation was afterwards manually curated by employing BLASTP and the Swiss-Prot, TrEMBL, and InterPro databases [50]. Prophage regions were identified using the online tool PHAST [51].

\section{Experiments with resting cells and acetate determination}

T. kivui was grown as described in $2 \times 500 \mathrm{ml}$ complex medium with $28 \mathrm{mM}$ glucose as carbon source to an $\mathrm{OD}_{600}$ of 1.9 to 2.4 . The culture was centrifuged anaerobically at $11,500 \times \mathrm{g}$ and $4^{\circ} \mathrm{C}$ for $10 \mathrm{~min}$. Cells were washed twice in imidazole buffer $(50 \mathrm{mM}$ imidazole, 
$20 \mathrm{mM} \mathrm{MgSO}$, $20 \mathrm{mM} \mathrm{KCl,} 4 \mathrm{mM}$ DTE, $4 \mu \mathrm{M}$ resazurin, $\mathrm{pH}$ 7.0). After the last centrifugation step, cells were resuspended in $2 \mathrm{ml}$ imidazole buffer. The protein concentration was determined according to [52], being approx. $100 \mathrm{mg} / \mathrm{ml}$. In order to determine the conversion of $\mathrm{H}_{2}+$ $\mathrm{CO}_{2}$ to acetate, 100-ml-serum flasks (Glasgerätebau Ochs $\mathrm{GmbH}$, Bovenden-Lenglern, Germany) were filled with $10 \mathrm{ml}$ imidazole buffer containing $50 \mathrm{mM} \mathrm{KHCO}_{3}$. If indicated, $\mathrm{NaCl}$ was added to a concentration of $20 \mathrm{mM}$. If applied, the ionophores ETH2120 and TCS were added to a concentration of $30 \mu \mathrm{M}$ each. Subsequently, the gas phase of the serum flasks was exchanged to 1 bar $\mathrm{H}_{2}+\mathrm{CO}_{2}$ $(80: 20[\mathrm{v} / \mathrm{v}])$ and then preheated to a temperature of $65^{\circ} \mathrm{C}$ in a water bath. The reaction was started by addition of resting cells to a final concentration of $1 \mathrm{mg} / \mathrm{ml}$. Henceforth, 500- $\mu$ l-samples were taken at time points as indicated. Samples were centrifuged immediately at 18,000 $\times$ g for $1 \mathrm{~min}$ and the supernatant was stored at $-20^{\circ} \mathrm{C}$. Determination of the acetate concentration of all samples was carried out using a commercially available kit (Acetic acid, Co. R-Biopharm, Darmstadt, Germany).

\section{Nucleotide sequences and accession number}

The sequence data described here have been deposited in GenBank under Acession No. CP009170 [GenBank: CP009170].

\section{Results}

\section{General features of the T. kivui genome}

The complete genome of T. kivui (accession number CP009170) consists of a circular chromosome with a size of 2.397 Mbp and an overall G + C content of $35.06 \mathrm{~mol} \%$. General features of the genome are listed in Table 1. We could identify 2378 putative protein-coding genes, three complete rRNA clusters and 58 tRNA genes. The tRNA necessary for incorporation of selenocystein is also present, but this organism is probably not able to assemble selenoproteins, since the $\operatorname{sel} A B C$ gene cluster coding

Table 1 General features of the $T$. kivui genome

\begin{tabular}{ll}
\hline & T. kivui \\
\hline Genome size & 2397289 bp \\
Protein encoding orfs & 2378 \\
Pseudo genes & 35 \\
Percent coding (\%) & 87.55 \\
G + C content (mol\%) & 35.06 \\
rRNA & 10 \\
tRNA & 58 \\
CDS with function prediction & 2024 \\
CDS without assigned function & 356 \\
CDS assigned to COGs & 1559 \\
CRISPR count & 3 \\
\hline
\end{tabular}

for essential proteins could not be identified, only a very short fragment of selB is present. $76.05 \%$ (1810) of the open reading frames (ORF) could be assigned to a putative function, 568 ORFs (23.86\%) were annotated as hypothetical proteins and 35 ORFs as pseudo genes. Approximately $61 \%$ (1551 ORFs) of all protein-encoding genes could be assigned to at least one of the 21 functional COGs (Cluster of Orthologous Groups). The two most abundant categories were "general function" and "amino acid transport and metabolism", to which $10.24 \%$ and $9.18 \%$, respectively, could be assigned to, followed by "function unknown", "translation, ribosomal structure and biogenesis", "coenzyme transport and metabolism", "replication, recombination and repair" and "energy production and conversion" with 9.06\%, 8.30\%, 6.83\%, 6.65\% and 6.00\%, respectively.

As mentioned before, "replication, recombination and repair" is one of the most abundant COG category in the genome of $T$. kivui. Proteins which were assigned to this category are Cas proteins (CRISPR-associated sequences) and the encoding genes are often located adjacent to CRISPR loci (Clustered Regularly Interspaced Short Palindromic Repeats). The CRISPR/Cas system protects the genome against invading mobile elements such as plasmids or phages and consists of contiguous repeats with different length (20 to 47) and different numbers [53-55]. The genome of $T$. kivui harbors 3 CRISPR loci with 35,48 and 21 repeats, respectively. The first CRISPR locus is flanked by four genes which could be assigned to a III-B/ polymerase-RAMP module CRISPR/Cas system subtype (TKV_c14620-TKV_c14650), the second locus is upstream flanked by a type III-B/polymerase-RAMP module subtype (TKV_c23500-TKV_c23560) and downstream by a hybrid cluster consisting of I-B/Teanap-Hmari and again a III-B/polymerase-RAMP module subtype where the cmr2 gene is interrupted by a transposase (TKV_c23590TKV_c23770), while a second I-B/Teanap-Hmari subtype CRISPR/Cas system is located adjacent to the third CRISPR locus (TKV_c24261). In addition we could identify a complete subtype III-A CRISPR/Cas system (TKV-c17330-TKV_c17390), which is not associated with a CRISPR locus. All CRISPR/Cas clusters were annotated according to the polythetic classification of CRISPR/Cas systems [56]. There is no complete prophage located on the chromosome of T. kivui.

\section{Substrate utilization}

T. kivui can not only grow autotrophically on $\mathrm{H}_{2}+\mathrm{CO}_{2}$ (or formate) but also heterotrophically on glucose, fructose, mannose, and pyruvate [33]. Correspondingly, genes coding for all enzymes for glycolysis were found in the $T$. kivui genome with only the hexokinase and the aldolase being encoded twice (Table 2). Despite the gene cluster TKV_c16300-TKV_c16340 (coding for the conversion of 
Table 2 Genes encoding enzymes of the Embden-MeyerhofParnas pathway

\begin{tabular}{ll}
\hline Enyzme & Locus tag \\
\hline Hexokinase & TKV_c00920, TKV_c17910 \\
Glucose-6-P isomerase & TKV_c16780 \\
6-phosphofructokinase & TKV_c16900 \\
Aldolase & TKV_c01430, TKV_c04080 \\
Triose-P isomerase & TKV_c16320 \\
Glycerinaldehyde-3-P deyhdrogenase & TKV_c16340 \\
Phosphoglycerate kinase & TKV_c16330 \\
Phosphoglycerate mutase & TKV_c16310 \\
Enolase & TKV_c16300 \\
Pyruvate kinase & TKV_c16890
\end{tabular}

glyceraldehyde-3-P to phosphoenolpyruvate), the genes are spread over the genome. Fructose is taken up and phosphorylated to fructose-1-P by a fructose-specific PTS system (TKV_c23130 and TKV_c23140). Interestingly, the genes encoding component IIB and IIC are fused to one gene, TKV_c23130. Subsequently, fructose-1-P is phosphorylated to fructose-1,6-bisphosphate by FruK (TKV_c2 3150), a 1-phosphofructokinase. On the other hand, mannose is taken up by a second, mannose-specific PTS system (TKV_c06180-TKV_c06200) and thereby activated to mannose-6-P. This substrate is converted to fructose-6-P by a mannose-6-P isomerase (TKV_c16180). Glycolysis results in the formation of pyruvate, which is most probably converted to acetyl-CoA by use of the pyruvate:ferredoxin oxidoreductase. A gene cluster (TKV_c19290TKV_c19260) encoding this enzyme was found in the genome of T. kivui, which encodes a ferredoxin, as well as the $\alpha, \beta$, and $\gamma$ subunit of the complex. Eventually, the phosphotransacetylase (TKV_c13970) and acetate kinase (TKV_c13960) catalyze the conversion of acetyl-CoA to acetate. Although two potential alcohol deyhdrogenases (TKV_c02600 and TKV_c22590) are encoded in the genome, an aldehyde dehydrogenase was not found. This is in accordance with the finding that ethanol was not detected in cells grown on $\mathrm{H}_{2}+\mathrm{CO}_{2}$, glucose or pyruvate [33].

\section{Genes involved in the Wood-Ljungdahl pathway}

The genes encoding the key enzymes in the WoodLjungdahl pathway of T. kivui are shown in Figure 1A. The first step in the methyl branch of the WLP is the reduction of $\mathrm{CO}_{2}$ to formate by a formate dehydrogenase. A corresponding gene cluster very similar to the one of $A$. woodii was found on the chromosome of T. kivui (TKV_c19950-TKV_c19990). In A. woodii, the cluster consists of 7 genes [57], with $f d h F 2$ being an isogene of $f d h F 1$, encoding a selenium-containing Fdh. A gene encoding an electron transfer protein $(h y c B)$ follows each $f d h$ gene. In T. kivui, only a selenium-free Fdh $(f d h F /$
TKV_c19990) is encoded in the cluster. This gene is followed by hycB3 (TKV_c19980) and hycB4 (TKV_c1 9970), both encoding small FeS proteins. Adjacent to hycB4 is a gene (hydA2/TKV_c19960) encoding a hydrogenase subunit. Both clusters also encode a gene annotated as $f d h D$. Since the enzyme purified from $A$. woodii did not contain an FdhD subunit [58], its function remains to be elucidated. In $A$. woodii, this enzyme complex was recently shown to catalyze the hitherto unknown reduction of $\mathrm{CO}_{2}$ with electrons coming directly from molecular hydrogen and was therefore named hydrogen-dependent $\mathrm{CO}_{2}$ reductase (HDCR) [58]. Thus, it is likely that T. kivui reduces $\mathrm{CO}_{2}$ to formate with $\mathrm{H}_{2}$ as well. This is in contrast to the close phylogenetic neighbor $M$. thermoacetica, which was shown to reduce $\mathrm{CO}_{2}$ with electrons coming from NADPH [59]. Many of the genes encoding functions of the WLP are located in one main gene cluster (Figure 1B), which lies in close proximity to the genes coding for the hydrogen-dependent $\mathrm{CO}_{2}$ reductase. The product of the first gene of the operon, fhs (TKV_c19930), probably catalyzes the initial ATP-dependent activation of formate to formyl-THF. Subsequent to $f h s$ is an open reading frame (orf1), whose product is similar to thymidylate synthases. Adjacent to orf1 are genes encoding the methenyl-THF cyclohydrolase $(f c h A)$, methylene-THF dehydrogenase $(f o l D)$ as well as two subunits of the methylene-THF reductase ( $m e t V$ and $m e t F)$. Those are followed by a dihydrolipoamide dehydrogenase $(p d h D)$, a maturation factor of the $\mathrm{CO}$ dehydrogenase $(\operatorname{coo} C)$, subunit beta $(a c s D)$ and subunit alpha $(\operatorname{acs} C)$ of the corrinoid iron-sulfur protein. The putative operon is completed by genes encoding a methyltransferase ( $a c s E)$, an acetyl-CoA synthase (acsB) and protein $\mathrm{H}$ of a glycine cleavage system $(g c v H)$. A possible function of GcvH within the WLP is unclear, but since this gene is also found within this gene cluster in $A$. woodii [57] and $M$. thermoacetica [30], one cannot exclude a so far undiscovered function of this enzyme within the pathway. Thus, as in $A$. woodii, proteins for the conversion of formate to methyl-THF are encoded by one gene cluster. However, in $A$. woodii folD and met $V$ do not lie adjacent to each other but are separated by the gene $r n f C 2$, probably coding for a third subunit of the methylene-THF reductase in this organism [57]. In $M$. thermoacetica, the genes coding for proteins of the methyl branch of the WLP are spread all over the genome. Only recently, MetF and MetV were shown to form a complex with the proteins $\mathrm{HdrABC}$ and MvhD [31]. Such genes were not found in T. kivui, implicating that the soluble methylene-THF reductase is composed of only 2 subunits. In $A$. woodii and $M$. thermoacetica, a separate gene cluster coding for the methyltransferase AcsE as well as subunits of the CODH/ACS is located somewhere else on the genome. In T. kivui, only two genes encoding a $\mathrm{CO}$ 


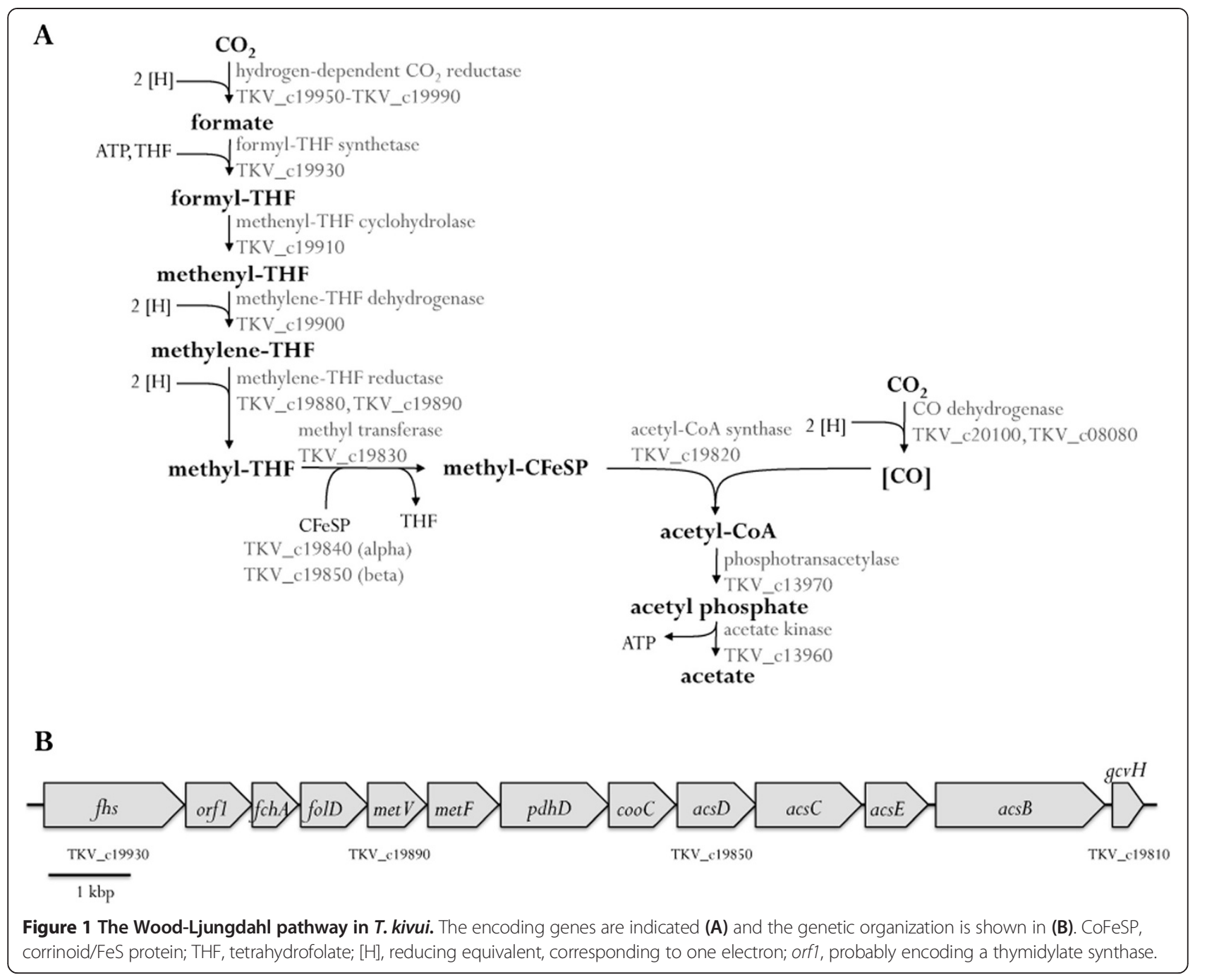

dehydrogenase (acsA/TKV_c20100 and cooS/TKV_c08080), a phosphotransacetylase and an acetate kinase are encoded elsewhere on the genome. Thus the WLP gene cluster is outstanding, since it encodes all proteins (despite AcsA, which is separated by 10 genes) that are required for the conversion of $\mathrm{CO}_{2}$ to acetyl-CoA.

\section{Transfer of reducing equivalents by soluble enzymes}

In all acetogens examined, ferredoxin and $\mathrm{NAD}(\mathrm{P})$ serve as common electron carriers in the WLP and in energy conservation. Reducing equivalents required in the WLP of T. kivui may be delivered from molecular hydrogen by a soluble electron bifurcating hydrogenase HydABC complex (TKV_c19580-TKV_c19600) similar to the electron bifurcating hydrogenases of $A$. woodii and $M$. thermoacetica, which reduce $\mathrm{NAD}^{+}$and ferredoxin in equimolar amounts [60-62]. HydA1 (TKV_c19850) of T. kivui shows $56 \%$ and $49 \%$ identity to the corresponding subunits of $M$. thermoacetica and A. woodii, respectively. The identities for HydB (TKV_c19590) to the homologous proteins of M. thermoacetica and A. woodii are $54 \%$ and $59 \%$, the ones for HydC (TKV_c19600) amount 42\% and 47\%, respectively. Apart from HydA2 of the HDCR and the HydABC complex, there is no other soluble hydrogenase encoded in the genome of T. kivui.

As also found in M. thermoacetica [32], the genome of T. kivui encodes an electron bifurcating transhydrogenase (NfnAB complex), which is encoded by the genes TKV_c22270 and TKV_c22280. TKV_c22270 shows 57\% and TKV_c22280 69\% identity to NfnA (Moth_1518) and NfnB (Moth_1517), respectively, from M. thermoacetica. In $M$.thermoacetica, this enzyme complex coupled the endergonic transfer of electrons from NADH to NADP ${ }^{+}$ to the exergonic reduction of $\mathrm{NADP}^{+}$with $\mathrm{Fd}_{\text {red }}$ [32].

\section{$\mathrm{F}_{1} \mathrm{~F}_{\mathrm{O}}$ ATP synthase of $T$. kivui}

ATP synthases consist of a soluble head domain, that catalyzes ATP synthesis or hydrolysis and a membrane domain that is responsible for ion translocation [63]. Genes encoding all the subunits of a $F_{1} F_{O}$ ATP synthase 
were found in the genome of T. kivui in one gene cluster (TKV_c06410-TKV_c06480). Interestingly, the cluster does not code for the gene atpI, which is the first gene of most bacterial atp operons and was shown to be essential for the assembly of the $c$ ring in A. woodii [64]. The genes flanking the ATP synthase gene cluster of T. kivui apparently do not code for proteins that are required for ATP synthesis.

The membrane-integral $c$ subunit of $\mathrm{F}_{1} \mathrm{~F}_{\mathrm{O}}$ ATP synthases determines the ion specificity of the enzyme. To check whether the $c$ subunit of $T$. kivui has a conserved $\mathrm{Na}^{+}$ binding site, sequence alignments of several $c$ subunits of $\mathrm{Na}^{+}$-dependent ATP synthases along with the one of $T$. kivui (atpE/TKV_c06420) were performed. As can be seen in Figure 2, the $\mathrm{Na}^{+}$-dependent $\mathrm{F}_{1} \mathrm{~F}_{\mathrm{O}}$ ATP synthases from Ilyobacter tartaricus, Propionigenium modestum and A. woodii have the conserved $\mathrm{Na}^{+}$binding motif consisting of the amino acids Q.....ES/T $[65,66]$. This motif cannot be found in the $c$ subunit of T. kivui (Figure 2). Here, the glutamine $(\mathrm{Q})$ is changed to an isoleucine (I) and instead of the serine $(\mathrm{S})$ or threonine $(\mathrm{T})$, there is an alanine $(\mathrm{A})$. Since the proton-binding site (E55) of the $c$ subunit is well conserved in T. kivui, this finding suggests that the $\mathrm{F}_{1} \mathrm{~F}_{\mathrm{O}}$ ATP synthase of T. kivui is $\mathrm{H}^{+}$-dependent. This finding is in line with the hypothesis that the bioenergetics of $T$. kivui is not based on a sodium ion but proton current across its cytoplasmic membrane. To substantiate this hypothesis, the effect of $\mathrm{Na}^{+}$on growth and acetate formation was analyzed.

\section{Autotrophic growth is not $\mathrm{Na}^{+}$-dependent}

In order to determine a $\mathrm{Na}^{+}$dependence of T. kivui during autotrophic growth, cells were transferred four times in $\mathrm{Na}^{+}$-depleted minimal medium, the contaminating amount of $\mathrm{Na}^{+}$was determined to $160 \pm 4 \mu \mathrm{M}, \mathrm{Na}^{+}$-enriched medium contained $71 \pm 1 \mathrm{mM} \mathrm{NaCl}$. As evident from Figure 3, the growth rate and the final optical density when growing on $\mathrm{H}_{2}+\mathrm{CO}_{2}$ were independent of the $\mathrm{Na}^{+}$concentration. Both cultures grew to an $\mathrm{OD}_{600}$ of $\sim 0.09$ within 30 hours. These data strongly support our hypothesis that T. kivui is not $\mathrm{Na}^{+}$- but $\mathrm{H}^{+}$-dependent.

\section{Acetate formation from $\mathrm{H}_{2}+\mathrm{CO}_{2}$ is $\mathrm{H}^{+}$-dependent}

In order to identify the nature of the coupling ion in acetogenesis of T. kivui irrevocably, cell suspensions of glucosegrown cells were prepared and acetate formation from $\mathrm{H}_{2}+\mathrm{CO}_{2}$ was determined. As evident from Figure 4A, the presence of $\mathrm{NaCl}$ had almost no effect on the final amount and rate of acetate formation, arguing against $\mathrm{Na}^{+}$as coupling ion. In contrast, the addition of $\mathrm{NaCl}$ even led to a slightly decreased acetate production rate. Without $\mathrm{NaCl}$ present in the system, the final amount of acetate was about $42 \mathrm{mM}$, whereas only $35 \mathrm{mM}$ acetate were produced in the presence of $20 \mathrm{mM} \mathrm{NaCl}$. The contaminating amount of $\mathrm{Na}^{+}$was $350 \pm 20 \mu \mathrm{M}$.

Although the experimentally determined $\mathrm{Na}^{+}$concentration in the assay without added $\mathrm{NaCl}$ is well below the $K_{\mathrm{M}}$ for $\mathrm{Na}^{+}$during acetate formation in $A$. woodii, it may well be that the $K_{\mathrm{M}}$ for $\mathrm{Na}^{+}$in T. kivui is lower than the contaminating $\mathrm{Na}^{+}$concentration in the assay. To determine whether acetogenesis in T. kivui relies on a transmembrane $\mathrm{Na}^{+}$or $\mathrm{H}^{+}$gradient, the effect of different ionophores on acetate formation was monitored. The $\mathrm{Na}^{+}$ionophore ETH2120 had almost no effect on acetate formation (in the absence or presence of sodium ions) (Figure 4B), whereas the protonophore TCS led to a complete inhibition of acetate formation. Here, the final amount of acetate was only $5 \mathrm{mM}$ (Figure 4C). The experiments with resting cells of T. kivui give strong evidence that T. kivui does not belong to the $\mathrm{Na}^{+}$-dependent acetogens, but that $\mathrm{H}^{+}$is the coupling ion.

\section{Membrane-embedded electron transfer coupled to the formation of a transmembrane proton gradient}

In $A$. woodii, the $\mathrm{Na}^{+}$-translocating $\mathrm{Rnf}$ complex is the only coupling site $[15,16,37]$. However, inspection of the genome and the absence of $\mathrm{Fd}_{\text {red: }}: \mathrm{NAD}^{+}$oxidoreductase activity at membranes of T. kivui (data not shown) revealed that $T$. kivui does neither possess an Rnf complex nor a complex with similar function. Furthermore, no genes encoding for cytochrome synthesis could be detected in the genome. Therefore, the genome of T. kivui was sought for genes encoding potential ion pumping membrane-bound oxidoreductases. As in M. thermoacetica, two gene clusters with 


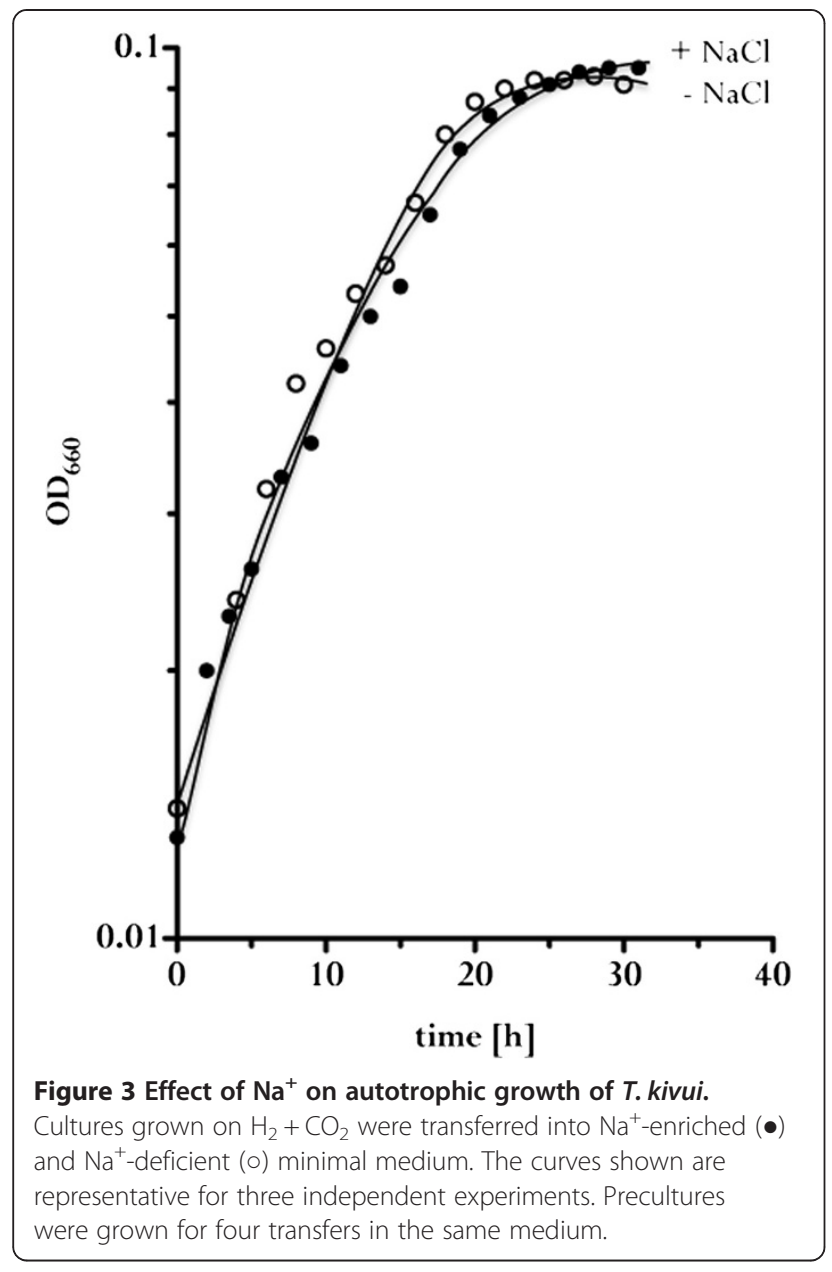

similarities to Ech-type complexes were found: TKV_c01 230-TKV_c01310 (Figure 5A) and TKV_c19750-TKV_c19 680 (Figure 6A). Ech complexes are thought to be the ancestor of complex I [67] and although final proof with a purified enzyme is still pending, strong indications were given that Ech complexes in methanogens couple the electron transfer from reduced ferredoxin to $\mathrm{H}^{+}$with the translocation of $\mathrm{H}^{+}$across the cytoplasmic membrane $[68,69]$. However, in M. thermoacetica, one Ech-type complex might be coupled to a formate dehydrogenase (Moth_2183) and the second does not possess all residues essential for a catalytic [NiFe] domain in the large hydrogenase subunit EchE (Moth_0980).

The first gene of the first ech gene cluster of T. kivui, ech1A (TKV_c01230), codes for a transmembrane protein with 19 predicted transmembrane helices with a weak similarity (17\%) to EchA from Methanosarcina barkeri. The identity to homologous proteins of $M$. thermoacetica is $21 \%$ to Moth_2191, 23\% to Moth_2188 and Moth_2187 (encoded by the first ech cluster), as well as $20 \%$ to Moth_0985 and 21\% to Moth_0986 and Moth_0987 (encoded by the second ech cluster). The product of the following gene, ech $1 B$, has 8 transmembrane helices and shows $21 \%$ identity to M. barkeri EchB, the identity to homologous proteins from $M$. thermoacetica is $22 \%$ for Moth 2190 and 26\% for Moth_0981. Both subunits are thought to be involved in $\mathrm{H}^{+}$transport $[70,71]$. ech1C codes for the small hydrogenase subunit, probably involved in electron transfer. The identity to M.barkeri EchC is $38 \%$, to M. thermoacetica Moth_2184 36\% and to Moth_0978 25\%. The fourth gene of the cluster, ech1F, encodes another subunit of Ech complexes. It has $24 \%$ identity to the corresponding subunit of M. barkeri and 26\% to the homologous subunits (Moth_2185 and Moth_0982, respectively) from $M$. thermoacetica. It is predicted to have two $4 \mathrm{Fe}-4 \mathrm{~S}$ clusters and therefore might be involved in electron transfer from ferredoxin. The following gene (hycB1/TKV_c01270) encodes a small FeS protein with four $4 \mathrm{Fe}-4 \mathrm{~S}$ clusters that shows homology to $\mathrm{HycB}$ from Escherichia coli (33\% identity) and CooF from Rhodospirillum rubrum (32\% identity). Its identity to the homologous protein from $M$. thermoacetica (Moth_2192) is $36 \%$. The protein products of the next two genes do not have any homologues in known Ech-type complexes, but show sequence similarity to the $\mathrm{N}$-terminus of MetV, the small subunit of the methylene-THF reductase of the Wood-Ljungdahl pathway. The sequence identity to each other is $22 \%$, the identity to MetV of T. kivui is $23 \%$ (for TKV_c01280) and 20\% (for TKV_c01290), respectively. Both proteins might coordinate one $4 \mathrm{Fe}-4 \mathrm{~S}$ cluster. 170 bp downstream of TKV_c01290 is a gene encoding the subunit Ech1D with 27\% identity to the corresponding subunit from M. barkeri. It has no predicted cofactors and its function in the complex is unknown so far. The genome of $M$. thermoacetica does not code for a homologous protein. Adjacent lies the gene ech1E, encoding the catalytic NiFe hydrogenase subunit. The protein sequence shows $40 \%$ identity to EchE from M. barkeri and 39\% and 33\% to Moth_2186 and Moth_0980, respectively, from $M$. thermoacetica. A model of the protein complex Ech1 encoded by this ech 1 cluster is shown in Figure 5B. Electrons coming from reduced ferredoxin may enter the complex at subunit Ech1F and may be transferred via the FeS proteins HycB1, TKV_c01280 and TKV_c01290 onto the catalytic hydrogenase subunit Ech1E that catalyzes $\mathrm{H}_{2}$ formation. Subunits Ech1A and Ech1B mediate $\mathrm{H}^{+}$transport across the cytoplasmic membrane.

The second gene cluster potentially encoding an Echtype hydrogenase is TKV_c19750-TKV_c19680 (Figure 6A). The product of the first gene, ech $2 D$, encodes a $14 \mathrm{kDa}$ protein (Figure 6B) and is 19\% identical to EchD from $M$. barkeri. The sequence identity to its homologue (TKV_c0 $1300)$ in the Ech 1 complex is only $8 \%$. The succeeding gene, ech $2 E$, codes for the large catalytic NiFe hydrogenase subunit and the deduced protein product shows $37 \%$ identity to M. barkeri EchE, $40 \%$ to Moth_2186 and 32\% to 

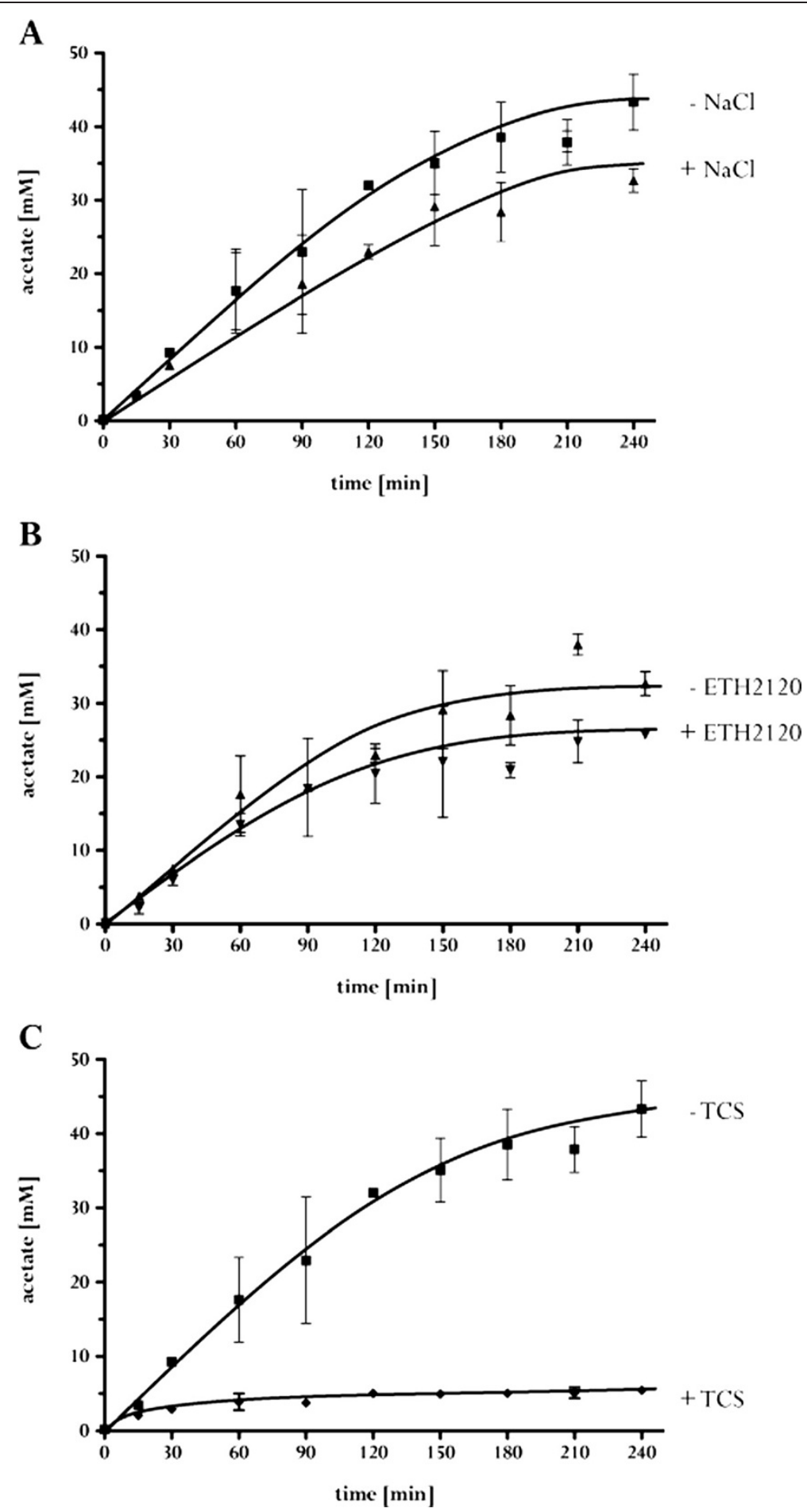

Figure 4 Acetate formation from $\mathrm{H}_{2}+\mathrm{CO}_{2}$ by resting cells of $T$. kivui is inhibited by TCS. Whole cells of T. kivui were incubated with $\mathrm{H}_{2}+$ $\mathrm{CO}_{2}$ in buffer containing $50 \mathrm{mM}$ imidazole, $20 \mathrm{mM} \mathrm{MgSO}_{4}, 20 \mathrm{mM} \mathrm{KCl}, 50 \mathrm{mM} \mathrm{KHCO}$ and $4 \mathrm{mM} \mathrm{DTE}$ (pH 7.0). A: $350 \pm 20 \mu \mathrm{M}(\mathbf{\square})$ or $20 \mathrm{mM}(\mathbf{\Delta})$

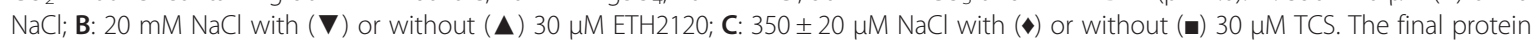
concentration of the resting cells in the assay was $1 \mathrm{mg} / \mathrm{ml}$. All values are mean from three replicates.

Moth_0980 from M. thermoacetica, as well as $45 \%$ to TKV_c01310/Ech1E from T. kivui. Thereafter lies a gene encoding a $13 \mathrm{kDa}$ protein $(\mathrm{HycB} 2)$ with four predicted
4Fe-4S clusters. It has $35 \%$ identity to the $\mathrm{FeS}$ protein HycB1 (TKV_c01270) of the above described Ech-type complex and is homologous to CooF from R. rubrum (36\% 


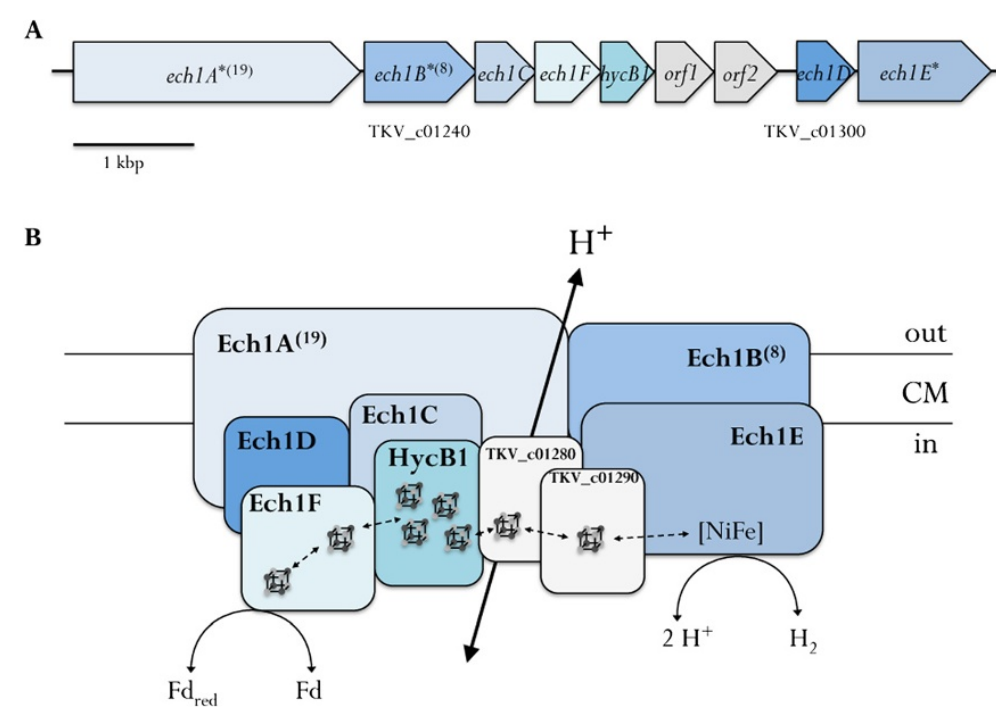

Figure 5 Arrangement of genes in the cluster (A) and model (B) of the Ech-type complex Ech1. Electron flow from reduced ferredoxin to $\mathrm{H}^{+}$and the coupled export of protons is shown. FeS clusters are indicated. ${ }^{*}$, predicted transmembrane protein (number of transmembrane helices); Fd, ferredoxin; orf1/orf2, encoding small FeS containing proteins (TKV_c01280 and TKV_C01290) with similarity to the N-terminus of MetV.

identity) and HycB from E. coli (39\% identity), as well. The next two genes, TKV_c19720 and TKV_c19710, both encode proteins similar to the membrane-bound subunit EchA (with $22 \%$ and $21 \%$ identity to $M$. barkeri EchA, respectively and 18 to $27 \%$ identity to the six EchA homologues from $M$. thermoacetica) and were therefore named ech $2 A 1$ and ech $2 A 2$. The homologue of Ech2A1 in complex I is NuoL, whereas the homologue of Ech2A2 is NuoM. Ech2C is encoded by the gene TKV_c19700. It has one hydrophobic stalk and represents the small hydrogenase subunit. Its identity to EchC from $M$. barkeri is $43 \%$, M. thermoacetica Moth_2184 and Moth_0978 are 48\% and 37\% identical. The gene ech $2 B$ encodes another membraneintegral subunit with 7 transmembrane helices but no known cofactors. Its identity to Moth_0981 is 25\%, sequence identity to Moth_2190 is only $17 \%$. The last gene encodes another small electron transfer protein with two $4 \mathrm{Fe}-4 \mathrm{~S}$ clusters and is similar to EchF, the identity to the corresponding proteins from $M$. thermoacetica is 28\% (Moth_2185) and 24\% (Moth_0982). A postulated subunit composition of the Ech2 complex

A

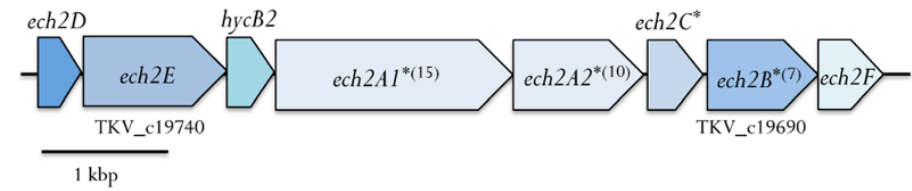

B

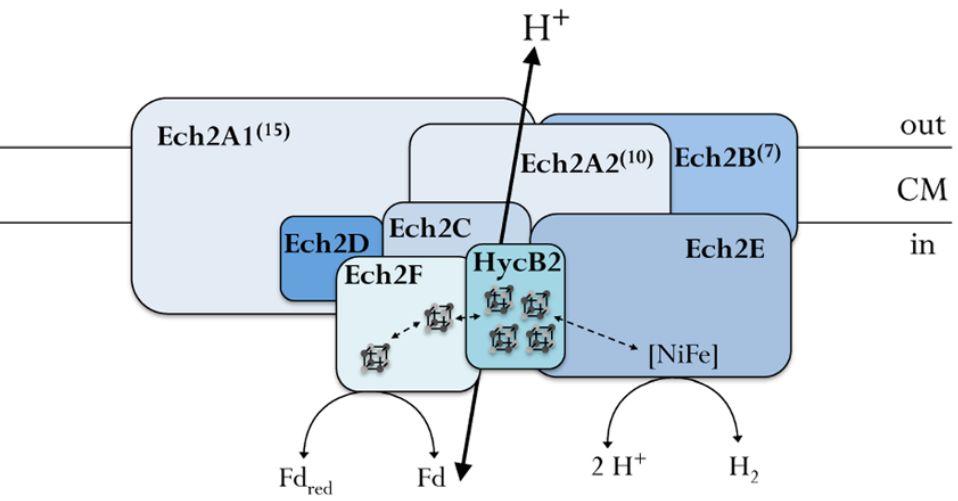

Figure 6 Arrangement of genes in the gene cluster (A) encoding a second potential Ech-type complex Ech2 (B). FeS clusters are indicated. *, predicted transmembrane protein (number of transmembrane helices); Fd, ferredoxin. 
and electron flow from reduced ferredoxin to $\mathrm{H}^{+}$with concomitant $\mathrm{H}^{+}$export is shown in Figure 6B.

Thus, in contrast to the above-described Ech-type complex, the second has one more membrane-integral subunit that might be involved in $\mathrm{H}^{+}$transport, probably allowing for a more beneficial stoichiometry of the electron: $\mathrm{H}^{+}$ratio. On the other hand, the small FeS proteins with similarity to MetV are missing. Sequence identities of the homologous proteins of the two Ech-type complexes to each other are summarized in Table 3.

\section{Discussion}

Model of energy conservation during autotrophic growth of $T$. kivui

The genomic data allow to propose a model for electron and carbon flow during acetogenesis from $\mathrm{H}_{2}+\mathrm{CO}_{2}$ in $T$. kivui. Electrons coming from molecular hydrogen are transferred to the electron carriers $\mathrm{NAD}^{+}$and ferredoxin by the soluble, electron-bifurcating hydrogenase HydABC. In the carbonyl branch of the WLP, the reduced ferredoxin serves as electron donor for the reduction of one molecule of $\mathrm{CO}_{2}$ to $\mathrm{CO}$, catalyzed by the CODH/ACS. In the methyl branch of the pathway, another $\mathrm{CO}_{2}$ is reduced to formate with electrons coming directly from molecular hydrogen. This reaction is catalyzed by the hydrogendependent $\mathrm{CO}_{2}$ reductase (HDCR), as it was also shown for A. woodii. The electron donor for the subsequent reduction of methenyl-THF cannot be predicted, since both NADH and NADPH are used in other acetogens and bioinformatic analyses do not allow to discriminate between the possibilities. However, since NADH is more common, it was used as electron donor for the T. kivui model. The following step, reduction of methylene-THF is still under debate for an indirect role in energy conservation. The redox potential $\left(\mathrm{E}^{0 \prime}\right)$ of the methylene-THF/methyl-THF pair is -200 to $-130 \mathrm{mV}$ [72] and electron transfer from NADH $\left(E^{0}=-320 \mathrm{mV}\right)$ to methylene-THF is highly exergonic. Therefore, this reaction was assumed already in 1977 to be involved in energy conservation [73]. One

\begin{tabular}{|c|c|c|c|}
\hline Locus tag 1 & Locus tag 2 & Protein subunit & Identity [\%] \\
\hline TKV_c19720 & TKV_c01230 & EchA & 22 \\
\hline TKV_c19710 & TKV_C01230 & EchA & 26 \\
\hline TKV_c19720 & TKV_C19710 & EchA & 18 \\
\hline TKV_c19690 & TKV_C01240 & EchB & 28 \\
\hline TKV_c19700 & TKV_C01250 & EchC & 50 \\
\hline TKV_c19750 & TKV_C01300 & EchD & 8 \\
\hline TKV_c19740 & TKV_c01310 & EchE & 45 \\
\hline TKV_c19680 & TKV_C01260 & EchF & 21 \\
\hline TKV_c19730 & TKV_c01270 & $\mathrm{HycB}$ & 35 \\
\hline
\end{tabular}

scenario is that methylene-THF reduction is coupled to ferredoxin reduction by electron bifurcation, as recently suggested for M. thermoacetica [31]. In T. kivui, MetV and MetF are encoded in the WLP operon (see Figure 1B), however, the genes encoding the putatively bifurcating Hdr subunits of M.thermoacetica are lacking in the $T$. kivui genome. Therefore, the situation is more similar to A. woodii, which is also lacking $\mathrm{Hdr}$-encoding genes and in which evidence for electron bifurcation was not obtained (Bertsch J, Öppinger C, Hess V, Langer ID, Müller V: A heterotrimeric $\mathrm{NADH}$-oxidizing methylenetetrahydrofolate reductase from the acetogenic bacterium Acetobacterium woodii, in preparation). Actually, MetV and MetF of T. kivui are the minimal subunit composition of an acetogenic, nonelectron-bifurcating methylene-THF reductase. Since cell-free extract of T. kivui does not catalyze NADH- or NADPHdependent methylene-THF reduction (data not shown) we assume an electron carrier in that redox range which may be, for example, a flavodoxin, which is energetically equivalent to $\mathrm{NADH}$. If we take into account a non-electron-bifurcating methylene-THF reductase that uses the electrons derived from a carrier energetically equivalent to $\mathrm{NADH}$ we can conclude a quantitative scheme for the bioenergetics of acetogenesis in T. kivui (Figure 7). According to this model, T. kivui can synthesize 0.25 ATP via the $\mathrm{F}_{1} \mathrm{~F}_{\mathrm{O}}$ ATP synthase per acetate formed.

The ATP:acetate ratio in the phylogenetically close neighbor M. thermoacetica is predicted to be 0.5 [19], thus in comparison, T. kivui conserves only half as much energy from $4 \mathrm{H}_{2}+2 \mathrm{CO}_{2}$. Both organisms have an electron bifurcating hydrogenase $\mathrm{HydABC}$ that couples initial $\mathrm{H}_{2}$ oxidation to the reduction of $\mathrm{NAD}^{+}$and ferredoxin. The latter is the electron donor for the energy conserving reaction, the electron flow to $\mathrm{H}^{+}$via the Ech complex that concomitantly translocates protons across the cytoplasmic membrane. The abovementioned difference in ATP production per acetate can be explained by the postulated additional coupling of methylene-THF reduction to the reduction of ferredoxin (or an energetic equivalent) in a second electron bifurcating reaction in M. thermoacetica. Hence this bacterium can transfer four electrons onto the Ech complex, thereby translocating two protons across the cytoplasmic membrane, whilst $T$. kivui uses the Ech complex only once per acetate formed.

As described in this paper, all data achieved are in accordance with $\mathrm{H}^{+}$based bioenergetics in T. kivui. Based on bioinformatic and experimental data, we could show that the ATP synthase is $\mathrm{H}^{+}$-dependent and the electrochemical ion gradient is probably formed by a $\mathrm{H}^{+}$-translocating Ech type complex. However, these data are in contrast to the results obtained by Yang et al. in 1990 [35], who found a strict $\mathrm{Na}^{+}$dependence when $\mathrm{H}_{2}$ was the electron donor. In order to assure our diverging results, we prepared our $\mathrm{Na}^{+}$-deficient medium strictly according to the instructions as given in [35]. We measured a contaminating $\mathrm{Na}^{+}$concentration of 


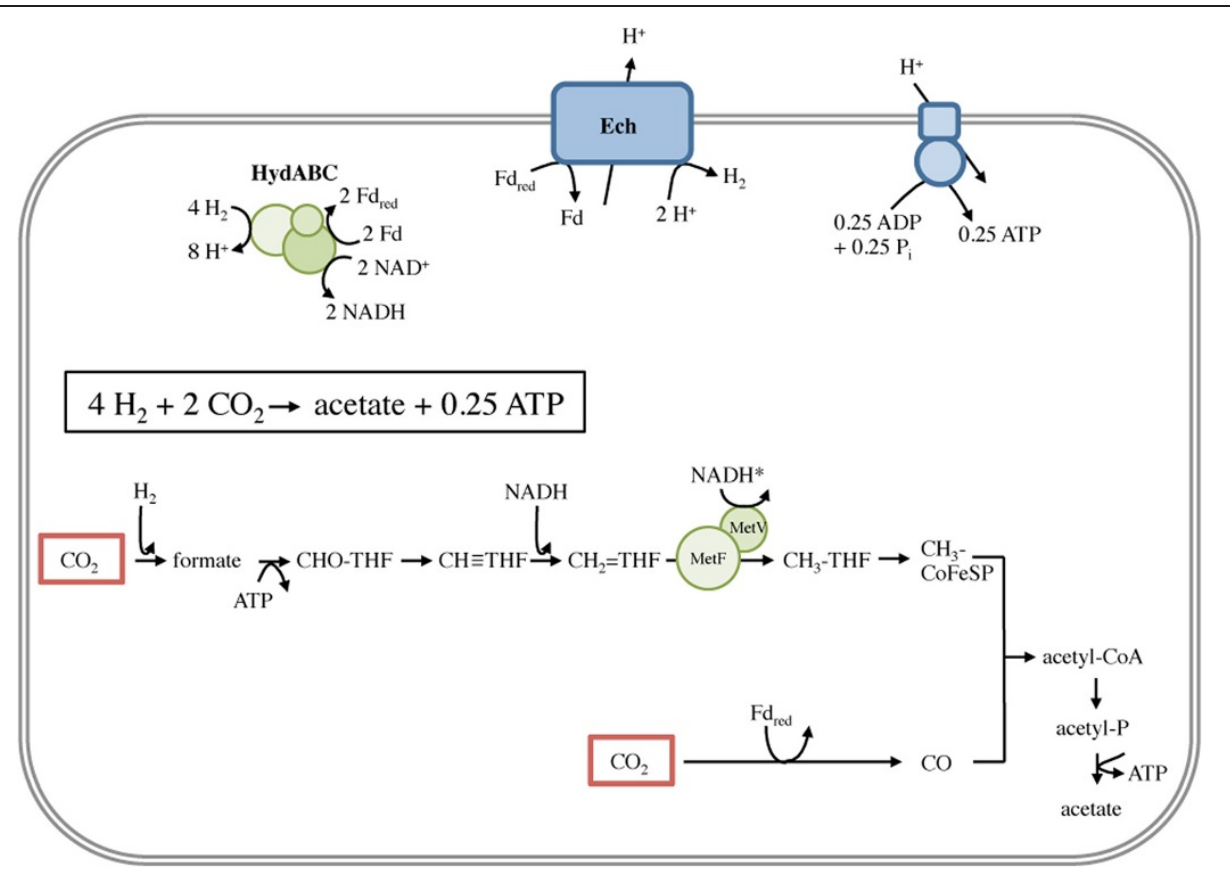

Figure 7 Model of electron and carbon flow in $T$. kivui when growing autotrophically. $\mathrm{Fd}_{\text {red, }}$ reduced ferredoxin; a $\mathrm{H}^{+} / \mathrm{ATP}$ ratio of $12 / 3$ was assumed for the $\mathrm{F}_{1} \mathrm{~F}_{\mathrm{O}}$ ATP synthase. *, reduction of methylene-THF might occur using an electron donor with a similar redox potential as NADH. CoFeSP, corrinoid/FeS protein.

$160 \mu \mathrm{M}$, while Yang and Drake reported $200 \mu \mathrm{M} \mathrm{NaCl}$ in their medium. Thus a different amount of $\mathrm{Na}^{+}$in the deficient medium can be excluded as a source of the discrepancy. We reproduced this experiment several times and could never see an effect of $\mathrm{Na}^{+}$on growth. Unfortunately, we were not able to find a reason for the discrepancy, but the additional data obtained in cell suspensions of T. kivui as well as the absence of a sodium ion binding site in the $c$ subunit of the $\mathrm{F}_{1} \mathrm{~F}_{\mathrm{O}}$ ATP synthase are consistent with the classification of T. kivui as $\mathrm{H}^{+}$-dependent.

In the early history of acetogenic bacteria, M. thermoacetica was used as a model organism to unravel the mechanism of energy conservation in $\mathrm{H}^{+}$-dependent acetogens. The detection of cytochromes [74] led to the assumption that $\mathrm{H}^{+}$translocation in M. thermoacetica is cytochrome-based [75-77]. However, despite many decades of intensive research, the participation of cytochromes in $\mathrm{H}^{+}$translocation of $M$. thermoacetica could never be confirmed and their involvement in energy conservation became questionable. Instead, a role of cytochromes in $\mathrm{O}_{2}$ reduction was discussed in recent years [32]. With our finding that T. kivui and M. thermoacetica seem to use very similar mechanisms for energy conservation and that the genome of T. kivui does not encode any proteins necessary for cytochrome synthesis, it becomes more and more evident that the function of cytochromes in $M$. thermoacetica is indeed not in energy conservation coupled to the WLP. Instead, we have recently proposed to classify the acetogens bioenergetically in Rnf- and Ech-containing acetogens [19] and each class has a subclass with $\mathrm{Na}^{+}-$and $\mathrm{H}^{+}$-dependent species. $T$. kivui thus belongs to the subclass of $\mathrm{H}^{+}$-depending, Echcontaining acetogens.

By further comparing the two acetogens T. kivui and $M$. thermoacetica, it is remarkable that, despite similar mechanisms for energy conservation, their growth behavior on $\mathrm{H}_{2}+\mathrm{CO}_{2}$ is quite different. As mentioned earlier, the doubling time of $M$. thermoacetica when growing autotrophically is about $24 \mathrm{~h}$ [32], while T. kivui grows 10-times faster [33]. But how can this discrepancy be explained in spite of the similar genetic configuration of the two bacteria? Since a weaker coupling of ATP synthesis and autotrophic acetate formation in M. thermoacetica was already excluded, the only explanation left is that at least one reaction of the Wood-Ljungdahl pathway is rate limiting. As M. thermoacetica is postulated to use three reactions that do not seem to be necessary in T. kivui (the transhydrogenase reaction for production of NADPH, reduction of $\mathrm{CO}_{2}$ with NADPH, and a bifurcating reaction in the course of methylene-THF reduction), one of those might well be the limiting factor. However, in order to irrevocably identify the bottleneck, extensive biochemical studies based on experimental data need to be carried out in future.

\section{Conclusions}

Sequencing the genome of T. kivui allowed for a better insight into the reactions enabling the autotrophic reduction of $\mathrm{CO}_{2}$ to acetate. Since this process is thought to be 
one of the first pathways that evolved on the early earth [78], its detailed understanding is of great relevance.

The thermophilic acetogen T. kivui oxidizes the electron donor $\mathrm{H}_{2}$ by use of an electron bifurcating hydrogenase HydABC. The reduced ferredoxin then fuels the energy conserving membrane module that is coupled to the WLP: the genome of T. kivui harbors two gene clusters, which both encode Ech-type complexes. Although the deduced protein subunit composition of the two complexes alter slightly, both enzymes have all cofactors and catalytic domains that are required to catalyze ferredoxin oxidation as well as $\mathrm{H}^{+}$reduction. The proton gradient formed by Ech can be used by a $\mathrm{H}^{+}$-dependent $\mathrm{F}_{1} \mathrm{~F}_{\mathrm{O}}$ ATP synthase to drive phosphorylation of ADP.

\section{Abbreviations \\ CODH/ACS: CO dehydrogenase/acetyl-CoA synthase; CoFeSP: Corrinoid/FeS protein; Ech: Energy conserving hydrogenase; ETH2120: Sodium ionophore III/N,N,N', N'-Tetracyclohexyl-1,2-phenylenedioxydiacetamide; Fd: Ferredoxin; PTS: Phosphotransferase system; TCS: 4',5-tetrachlorosalicylanilide; THF: Tetrahydrofolate; WLP: Wood-Ljungdahl pathway.}

\section{Competing interests}

The authors declare that they have no competing interests.

\section{Authors' contributions}

$\mathrm{AP}$ and $\mathrm{RD}$ planned the genome sequencing, AP did the genome sequencing, AP did the genome annotations, VH and MCW analyzed the data, $\mathrm{VH}$ and $\mathrm{VM}$ conceived and designed the experiments, $\mathrm{VH}$ provided the experimental data, $\mathrm{VH}$ prepared the figures, $\mathrm{VH}, \mathrm{AP}$ and $\mathrm{VM}$ wrote the manuscript. All authors read and approved the final manuscript.

\section{Acknowledgments}

This work was supported by a grant from the Deutsche Forschungsgemeinschaft. We thank Frauke-Dorthee Meyer for technical support.

\section{Author details}

'Department of Molecular Microbiology \& Bioenergetics, Institute of Molecular Biosciences, Johann Wolfgang Goethe University Frankfurt/Main, Max-von-Laue-Str. 9, 60438 Frankfurt, Germany. ${ }^{2}$ Department of Genomic and Applied Microbiology, Göttingen Genomics Laboratory, Georg August University, Institute for Microbiology and Genetics, Grisebachstraße 8, 37077 Göttingen, Germany.

Received: 2 October 2014 Accepted: 12 December 2014

Published: 18 December 2014

\section{References}

1. Drake HL, Gößner AS, Daniel SL: Old acetogens, new light. Ann N Y Acad Sci 2008, 1125:100-128.

2. Müller V, Frerichs J: Acetogenic bacteria. In eLS. Edited by Battista J. Chichester: John Wiley \& Sons Ltd; 2013 [doi:10.1002/9780470015902. a0020086.pub2].

3. Ljungdahl LG: The acetyl-CoA pathway and the chemiosmotic generation of ATP during acetogenesis. In Acetogenesis. Edited by Drake HL. New York: Chapman \& Hall; 1994:63-87.

4. Ragsdale SW: Enzymology of the Wood-Ljungdahl pathway of acetogenesis. Ann N Y Acad Sci 2008, 1125:129-136.

5. Pezacka $\mathrm{E}$, Wood $\mathrm{HG}$ : Role of carbon monoxide dehydrogenase in the autotrophic pathway used by acetogenic bacteria. Proc Natl Acad Sci U S A 1984, 81:6261-6265.

6. Raybuck SA, Bastian NR, Orme-Johnson WH, Walsh CT: Kinetic characterization of the carbon monoxide-acetyl-CoA (carbonyl group) exchange activity of the acetyl-CoA synthesizing $\mathrm{CO}$ dehydrogenase from Clostridium thermoaceticum. Biochemistry 1988, 27:7698-7702.

7. Seravalli J, Kumar M, Lu WP, Ragsdale SW: Mechanism of carbon monoxide oxidation by the carbon monoxide dehydrogenase/acetyl-CoA synthase from Clostridium thermoaceticum: Kinetic characterization of the intermediates. Biochemistry 1997, 36:11241-11251.

8. Himes RH, Harmony JA: Formyltetrahydrofolate synthetase. $\mathrm{CrC} \mathrm{Cr} \mathrm{Rev}$ Bioch Mol 1973, 1:501-535.

9. Lovell CR, Przybyla A, Ljungdahl LG: Cloning and expression in Escherichia coli of the Clostridium thermoaceticum gene encoding thermostable formyltetrahydrofolate synthetase. Arch Microbiol 1988, 149:280-285.

10. Ragsdale SW, Ljungdahl LG, DerVartanian DV: EPR evidence for nickel-substrate interaction in carbon monoxide dehydrogenase from Clostridium thermoaceticum. Biochem Biophys Res Commun 1982, 108:658-663.

11. Ragsdale SW, Ljungdahl LG, DerVartanian DV: Isolation of carbon monoxide dehydrogenase from Acetobacterium woodii and comparison of its properties with those of the Clostridium thermoaceticum enzyme. J Bacteriol 1983, 155:1224-1237.

12. Ragsdale SW, Wood HG: Acetate biosynthesis by acetogenic bacteria. Evidence that carbon monoxide dehydrogenase is the condensing enzyme that catalyzes the final steps in the synthesis. J Biol Chem 1985, 260:3970-3977.

13. Schaupp A, Ljungdahl LG: Purification and properties of acetate kinase from Clostridium thermoaceticum. Arch Microbiol 1974, 100:121-129.

14. Eden $\mathrm{G}$, Fuchs $\mathrm{G}$ : Total synthesis of acetyl coenzyme $A$ involved in autotrophic $\mathrm{CO}_{2}$ fixation in Acetobacterium woodii. Arch Microbiol 1982, 133:66-74.

15. Biegel E, Schmidt S, González JM, Müller V: Biochemistry, evolution and physiological function of the Rnf complex, a novel ion-motive electron transport complex in prokaryotes. Cell Mol Life Sci 2011, 68:613-634.

16. Biegel $\mathrm{E}$, Müller $\mathrm{V}$ : Bacterial $\mathrm{Na}^{+}$-translocating ferredoxin: $\mathrm{NAD}^{+}$ oxidoreductase. Proc Natl Acad Sci U S A 2010, 107:18138-18142.

17. Heise R, Reidlinger J, Müller V, Gottschalk G: A sodium-stimulated ATP synthase in the acetogenic bacterium Acetobacterium woodii. FEBS Lett 1991, 295:119-122

18. Müller $\mathrm{V}$, Aufurth $\mathrm{S}$, Rahlfs $\mathrm{S}$ : The $\mathrm{Na}^{+}$cycle in Acetobacterium woodii: identification and characterization of a $\mathrm{Na}^{+}$-translocating $\mathrm{F}_{1} \mathrm{~F}_{\mathrm{O}}$-ATPase with a mixed oligomer of 8 and $16 \mathrm{kDa}$ proteolipids. Biochim Biophys Acta 2001, 1505:108-120.

19. Schuchmann K, Müller V: Autotrophy at the thermodynamic limit of life: a model for energy conservation in acetogenic bacteria. Nat Rev Microbiol 2014, 12:809-821.

20. Fröstl JM, Seifritz C, Drake HL: Effect of nitrate on the autotrophic metabolism of the acetogens Clostridium thermoautotrophicum and Clostridium thermoaceticum. J Bacteriol 1996, 178:4597-4603.

21. Seifritz C, Daniel SL, Gössner A, Drake HL: Nitrate as a preferred electron sink for the acetogen Clostridium thermoaceticum. J Bacteriol 1993, 175:8008-8013.

22. Dilling S, Imkamp F, Schmidt S, Müller V: Regulation of caffeate respiration in the acetogenic bacterium Acetobacterium woodii. Appl Environ Microbiol 2007, 73:3630-3636.

23. Misoph M, Daniel SL, Drake HL: Bidirectional usage of ferulate by the acetogen Peptostreptococcus productus U-1: $\mathrm{CO}_{2}$ and aromatic acrylate groups as competing electron accepters. Microbiology-Uk 1996, 142:1983-1988.

24. Gössner A, Daniel SL, Drake HL: Acetogenesis coupled to the oxidation of aromatic aldehyde groups. Arch Microbiol 1994, 161:126-131.

25. Matthies $C$, Freiberger A, Drake HL: Fumarate dissimilation and differential reductant flow by Clostridium formicoaceticum and Clostridium aceticum. Arch Microbiol 1993, 160:273-278.

26. Tanner RS, Miller LM, Yang D: Clostridium ljungdahlii sp. nov., an acetogenic species in clostridial rRNA homology Group-I. Int J Syst Bact 1993, 43:232-236

27. Liou JS, Balkwill DL, Drake GR, Tanner RS: Clostridium carboxidivorans sp. nov., a solvent-producing clostridium isolated from an agricultural settling lagoon, and reclassification of the acetogen Clostridium scatologenes strain SL1 as Clostridium drakei sp. nov. Int I Syst Evol Microbiol 2005, 55:2085-2091.

28. Schiel-Bengelsdorf B, Dürre P: Pathway engineering and synthetic biology using acetogens. FEBS Lett 2012, 586:2191-2198.

29. Köpke M, Mihalcea C, Liew F, Tizard JH, Ali MS, Conolly JJ, Al-Sinawi B, Simpson SD: 2,3-butanediol production by acetogenic bacteria, an alternative route to chemical synthesis, using industrial waste gas. Appl Environ Microbiol 2011, 77:5467-5475. 
30. Pierce E, Xie G, Barabote RD, Saunders E, Han CS, Detter JC, Richardson P, Brettin TS, Das A, Ljungdahl LG, Ragsdale SW: The complete genome sequence of Moorella thermoacetica (f. Clostridium thermoaceticum). Environ Microbiol 2008, 10:2550-2573.

31. Mock J, Wang S, Huang H, Kahnt J, Thauer RK: Evidence for a hexaheteromeric methylenetetrahydrofolate reductase in Moorella thermoacetica. J Bacteriol 2014, 196:3303-3314.

32. Huang $\mathrm{H}$, Wang $\mathrm{S}$, Moll J, Thauer RK: Electron bifurcation involved in the energy metabolism of the acetogenic bacterium Moorella thermoacetica growing on glucose or $\mathrm{H}_{2}$ plus $\mathrm{CO}_{2}$. J Bacteriol 2012, 194:3689-3699.

33. Leigh JA, Mayer F, Wolfe RS: Acetogenium kivui, a new thermophilic hydrogen-oxidizing, acetogenic bacterium. Arch Microbiol 1981, 129:275-280.

34. Daniel SL, Hsu T, Dean SI, Drake HL: Characterization of the $\mathrm{H}_{2}$-dependent and CO-dependent chemolithotrophic potentials of the acetogens Clostridium thermoaceticum and Acetogenium kivui. J Bacteriol 1990, 172:4464-4471.

35. Yang H, Drake HL: Differential effects of sodium on hydrogen- and glucose-dependent growth of the acetogenic bacterium Acetogenium kivui. Appl Environ Microbiol 1990, 56:81-86.

36. Bradford MM: A rapid and sensitive method for the quantification of microgram quantities of protein utilizing the principle of proteine-dye-binding. Anal Biochem 1976, 72:248-254.

37. Hess $V$, Schuchmann $K$, Müller $V$ : The ferredoxin:NAD ${ }^{+}$oxidoreductase (Rnf) from the acetogen Acetobacterium woodii requires $\mathrm{Na}^{+}$and is reversibly coupled to the membrane potential. J Biol Chem 2013, 288:31496-31502.

38. Schönheit $P$, Wäscher $C$, Thauer RK: A rapid procedure for the purification of ferredoxin from clostridia using polyethylenimine. FEBS Lett 1978, 89:219-222.

39. Murray MG, Thompson WF: Rapid isolation of high molecular weight plant DNA. Nucleic Acids Res 1980, 8:4321-4325.

40. Wilson K: Preparation of genomic DNA from bacteria. In Current Protocols in Molecular Biology. Edited by Ausubel FM. Hoboken: John Wiley \& Sons, Inc; 2001:56:2.4.1.-2.4.5

41. Chevreux B: MIRA: an automated genome and EST assembler. Ruprecht-Karls University; Heidelberg, 2005.

42. Darling AE, Mau B, Perna NT: progressiveMauve: multiple genome alignment with gene gain, loss and rearrangement. PLoS One 2010, 5:e11147.

43. Markowitz VM, Chen IM, Palaniappan K, Chu K, Szeto E, Pillay M, Ratner A, Huang J, Woyke T, Huntemann M, Anderson I, Billis K, Varghese N, Mavromatis K, Pati A, Ivanova NN, Kyrpides NC: IMG 4 version of the integrated microbial genomes comparative analysis system. Nucleic Acids Res 2014, 42:D560-D567.

44. Markowitz VM, Chen IM, Palaniappan K, Chu K, Szeto E, Grechkin Y, Ratner A, Jacob B, Huang J, Williams P, Huntemann M, Anderson I, Mavromatis K, Ivanova NN, Kyprides NC: IMG: the Integrated Microbial Genomes database and comparative analysis system. Nucleic Acids Res 2012, 40:D115-D122.

45. Tettelin H, Radune D, Kasif S, Khouri H, Salzberg SL: Optimized multiplex PCR: efficiently closing a whole-genome shotgun sequencing project Genomics 1999, 62:500-507.

46. Staden R, Beal KF, Bonfield JK: The Staden package, 1998. Methods Mol Biol 2000, 132:115-130

47. Hyatt D, Chen GL, Locascio PF, Land ML, Larimer FW, Hauser L: Prodigal: prokaryotic gene recognition and translation initiation site identification. BMC Bioinformatics 2010, 11:119.

48. Lagesen K, Hallin P, Rodland EA, Staerfeldt HH, Rognes T, Ussery DW: RNAmmer: consistent and rapid annotation of ribosomal RNA genes. Nucleic Acids Res 2007, 35:3100-3108.

49. Lowe TM, Eddy SR: tRNAscan-SE: a program for improved detection of transfer RNA genes in genomic sequence. Nucleic Acids Res 1997, 25:955-964.

50. Zdobnov EM, Apweiler R: InterProScan-an integration platform for the signature-recognition methods in InterPro. Bioinformatics 2001, 17:847-848.

51. Zhou Y, Liang Y, Lynch KH, Dennis JJ, Wishart DS: PHAST: a fast phage search tool. Nucleic Acids Res 2011, 39:W347-W352.

52. Schmidt K, Liaaen Jensen S, Schlegel HG: Die Carotinoide der Thiorhodaceae. I Okenon als Hauptcarotinoid von Chromatium okenii Perty. Arch Mikrobiol 1963, 46:117-126.

53. Horvath $P$, Barrangou R: CRISPR/Cas, the immune system of bacteria and archaea. Science 2010, 327:167-170

54. Haft DH, Selengut J, Mongodin EF, Nelson KE: A guild of 45 CRISPRassociated (Cas) protein families and multiple CRISPR/Cas subtypes exist in prokaryotic genomes. PLoS Comput Biol 2005, 1:e60.
55. Westra ER, Brouns SJ: The rise and fall of CRISPRs-dynamics of spacer acquisition and loss. Mol Microbiol 2012, 85:1021-1025.

56. Makarova KS, Haft DH, Barrangou R, Brouns SJ, Charpentier E, Horvath P, Moineau S, Mojica FJ, Wolf Yl, Yakunin AF, van der Oost J, Koonin EV: Evolution and classification of the CRISPR-Cas systems. Nat Rev Microbiol 2011, 9:467-477.

57. Poehlein A, Schmidt S, Kaster A-K, Goenrich M, Vollmers J, Thürmer A, Bertsch J, Schuchmann K, Voigt B, Hecker M, Daniel R, Thauer RK, Gottschalk G, Müller V: An ancient pathway combining carbon dioxide fixation with the generation and utilization of a sodium ion gradient for ATP synthesis. Plos One 2012, 7:e33439.

58. Schuchmann $\mathrm{K}$, Müller $\mathrm{V}$ : Direct and reversible hydrogenation of $\mathrm{CO}_{2}$ to formate by a bacterial carbon dioxide reductase. Science 2013, 342:1382-1385.

59. Li LF, Ljungdahl L, Wood HG: Properties of nicotinamide adenine dinucleotide phosphate-dependent formate dehydrogenase from Clostridium thermoaceticum. J Bacteriol 1966, 92:405-412

60. Schuchmann K, Müller V: A bacterial electron bifurcating hydrogenase. J Biol Chem 2012, 287:31165-31171.

61. Schut GJ, Adams MW: The iron-hydrogenase of Thermotoga maritima utilizes ferredoxin and NADH synergistically: a new perspective on anaerobic hydrogen production. J Bacterio/ 2009, 191:4451-4457.

62. Wang $\mathrm{S}$, Huang $\mathrm{H}$, Kahnt J, Thauer RK: A reversible electron-bifurcating ferredoxin- and NAD-dependent [FeFe]-hydrogenase (HydABC) in Moorella thermoacetica. J Bacteriol 2013, 195:1267-1275.

63. Müller V, Grüber G: ATP synthases: structure, function and evolution of unique energy converters. Cell Mol Life Sci 2003, 60:474-494.

64. Brandt K, Müller DB, Hoffmann J, Hübert C, Brutschy B, Deckers-Hebestreit G, Müller $V$ : Functional production of the $\mathrm{Na}^{+} \mathrm{F}_{1} \mathrm{~F}_{\mathrm{O}}$ ATP synthase from Acetobacterium woodii in Escherichia coli requires the native Atpl. J Bioenerg Biomembr 2013, 45:15-23.

65. Rahlfs $\mathrm{S}$, Aufurth $\mathrm{S}$, Müller $\mathrm{V}$ : The $\mathrm{Na}^{+}-\mathrm{F}_{1} \mathrm{~F}_{\mathrm{O}}$-ATPase operon from Acetobacterium woodii. Operon structure and presence of multiple copies of atpE which encode proteolipids of 8- and 18-kDa. J Biol Chem 1999, 274:33999-34004.

66. Meier T, Krah A, Bond PJ, Pogoryelov D, Diederichs K, Faraldo-Gómez JD: Complete ion-coordination structure in the rotor ring of $\mathrm{Na}^{+}$-dependent F-ATP synthases. J Mol Biol 2009, 391:498-507.

67. Hedderich R: Energy-converting [NiFe] hydrogenases from archaea and extremophiles: ancestors of complex I. J Bioenerg Biomembr 2004, 36:65-75.

68. Welte C, Krätzer C, Deppenmeier U: Involvement of Ech hydrogenase in energy conservation of Methanosarcina mazei. FEBS J 2010, 277:3396-3403.

69. Meuer J, Bartoschek S, Koch J, Künkel A, Hedderich R: Purification and catalytic properties of Ech hydrogenase from Methanosarcina barkeri. Eur J Biochem 1999, 265:325-335.

70. Welte C, Deppenmeier U: Bioenergetics and anaerobic respiratory chains of aceticlastic methanogens. Biochim Biophys Acta 2013, 1837:1130-1147.

71. Hedderich R, Forzi L: Energy-converting [NiFe] hydrogenases: more than just $\mathrm{H}_{2}$ activation. J Mol Microbiol Biotechnol 2005, 10:92-104.

72. Maden BE: Tetrahydrofolate and tetrahydromethanopterin compared: functionally distinct carriers in $C_{1}$ metabolism. Biochem J 2000, 350:609-629.

73. Thauer RK, Jungermann K, Decker K: Energy conservation in chemotrophic anaerobic bacteria. Bact Rev 1977, 41:100-180.

74. Gottwald M, Andreesen JR, LeGall J, Ljungdahl LG: Presence of cytochrome and menaquinone in Clostridium formicoaceticum and Clostridium thermoaceticum. J Bacteriol 1975, 122:325-328.

75. Hugenholtz J, Ivey DM, Ljungdahl LG: Carbon monoxide-driven electron transport in Clostridium thermoautotrophicum membranes. J Bacteriol 1987, 169:5845-5847

76. Hugenholtz J, Ljungdahl LG: Electron transport and electrochemical proton gradient in membrane vesicles of Clostridium thermoaceticum. J Bacteriol 1989, 171:2873-2875.

77. Hugenholtz J, Ljungdahl LG: Amino acid transport in membrane vesicles of Clostridium thermoautotrophicum. FEMS Microbiol Lett 1990, 69:117-122.

78. Martin WF: Hydrogen, metals, bifurcating electrons, and proton gradients: the early evolution of biological energy conservation. FEBS Lett 2012, 586:485-493.

doi:10.1186/1471-2164-15-1139

Cite this article as: Hess et al:: A genome-guided analysis of energy conservation in the thermophilic, cytochrome-free acetogenic bacterium Thermoanaerobacter kivui. BMC Genomics 2014 15:1139. 